by obese patients. . . . In a study of the effect of pharmacological doses of T3 and T4, mean maximum doses tolerated were $275 \mu \mathrm{g}$ a day and $1.5 \mathrm{mg}$."

Referring to the proceedings of an international conference on thyroid published by Excerpta Medica in 1975, he explained that the paper showed that, in the case of euthyroid patients, if more exogenous thyroxine is given the disposal rate of thyroxine increases and, up to certain limits, becomes equivalent to the amount of thyroxine that is given, correcting for the absorption rate. He cited several other recent studies dealing with euthyroid subjects who had received large doses of thyroid hormone without suffering harm. He also produced authorities for his contention that patients on a diet such as his suffer a fall in triiodothyronine concentrations.

\section{Satisfied patients}

Dr Gee's first witness, Christina Osbourne, a patient, gave evidence about the visit of representatives of the BBC to Dr Gee's Rochester premises, when she was waiting for a consultation. When Mr Geoffrey Shaw, junior counsel for Dr Gee, began in his re-examination tõ question Mrs Osbourne about her treatment by Dr Gee, Mr Charles Gray QC, leading counsel for the two doctors sued by Dr Gee over their part in the That's Life broadcast, rose to object.

Mr Gray submitted that evidence from patients other than those referred to in the pleadings of the case about, for example, the sort of examination $\mathrm{Dr}$ Gee gave them was inadmissible. It had been suggested, he said, that Dr Gee was proposing to call 20 or 30 "satisfied patients."

Legal argument over the admissibility of this evidence was interrupted to hear evidence from several other witnesses who had been waiting to give evidence. One former patient, Hildegarde Convery, said she had consulted Dr Gee after her general practitioner had told her to lose weight after two heart attacks. At her general practitioner's request she had asked Dr Gee to write down the names of the drugs he gave her, and he had done so. Her doctor had told her the treatment was all right. She said she had been taking Soni-Slo (isosorbide dinitrate) for her heart condition. She had told Dr Gee about her heart attacks but she could not remember whether he had asked what sort of tablets she was taking or whether he had asked if she was receiving treatment from her own doctor.

After two days of legal argument Lord Justice Croom-Johnson ruled that the evidence of the satisfied patients was not admissible unless and until it became relevant later in the proceedings. This might happen, he said, if the defendants' expert evidence was given in such a form that it made the evidence of the satisfied patients relevant to test those opinions. If this happened $\mathrm{Mr}$ Beloff could apply to call the patients' evidence in rebuttal. One instance canvassed in cross examination was the suggestion that, in giving the thyroid dosage he did, Dr Gee was making most of his patients thyrotoxic. That was the kind of issue on which this sort of evidence in rebuttal might perhaps be relevant in the future. His Lordship said his ruling applied only to the patients treated for obesity, and, before the adjournment, several of Dr Gee's general patients testified to their satisfaction with his treatment.

\title{
Rationing of resources
}

\section{BY OUR LEGAL CORRESPONDENT}

Rationing of medical resources is not new. But where treatment is theoretically available equally to all problems arise which are not present where the means of the patient limit allocation of resources. Heightened expectations of both patients and doctors raise questions of legal liability to patients denied a particular treatment on grounds of expense or unavailability.

Minerva tells us that someone described as a health economist argues that doctors must recognise a duty to the community which at times may clash with their wish to do their best for each of their patients: "obtaining scarce resources for an individual patient clearly reduces their availability to others-and doctors should recognise their obligation to consider their common good."'

On an ethical level it may be doubtful whether doctors should deprive their individual patients of a needed treatment because of an appreciation (which must be imperfectly informed) of the needs of "the community," which presumably means other doctors' patients, whose relative needs are unknown to the rationing doctor. Is it not the doctor's ethical duty to fight for his patients and let other doctors fight for theirs? If they meekly cooperate in dividing the cake presented to them, they will never be given a bigger cake. But sometimes with the resources at his disposal a doctor has to choose between one and another of his own patients. In one area this has led to the adoption into the medical vocabulary of the eighteenth century word "triage," defined in the Shorter Oxford English Dictionary as "the action of assorting according to quality." That definition evokes memories of a recent decision to deny kidney dialysis to a patient who supposedly had an inadequate quality of life. any?
If a doctor follows advice that because of an "uneconomic return" he should not screen all his women patients for cervical cancer is he liable in damages to those patients who have suffered from the failure to make an early diagnosis which could have been made? If a hospital has facilities to treat only 10 patients with kidney disease, should the hospital, or perhaps the Secretary of State, be liable to the 11 th, who is refused treatment? One would think that if the interests of the state as determined by "health economists" require that available prophylactic measures should not be taken, or that life lengthening treatments should not be given to all whose lives would be lengthened, at least those individuals who suffered from that policy (or their heirs) should receive compensation from the state. It may be that if just compensation to those individuals who suffer from a decision not to undertake a mass screening programme were brought into the balance, the screening would after all be seen to be economic. If the "quality of life" choice were followed, perhaps some economic logic might emerge whereby those who would recover heavy damages if not treated would be given treatment, and those whose damages would be small would be left to their remedy in damages. Those who find such a method revolting should put forward better methods to make the inevitable selection.

What is the legal position of the Secretary of State? In an unreported decision of the Court of Appeal (the transcript of which may be read in the Supreme Court Library ${ }^{1}$ ) the court considered an application by four orthopaedic patients at a Birmingham hospital who had waited for treatment for longer than was medically advisable. Delay was caused partly by a decision determined by costs not to build a new hospital block. The patients sued the Secretary of State, the regional health authority, 
and the area health authority claiming declarations that the defendants were in breach of duty under sections 1 and 3 of the National Health Act 1977, and also claiming damages.

Section 1 of the 1977 Act laid on the Secretary of State the duty to continue the promotion of comprehensive health service designed to secure improvement both in the physical and mental health of the people and in the prevention, diagnosis, and treatment of illness. Section 3 lays on the Secretary of State the duty to provide certain specific facilities (such as hospital accommodation) and certain services, but the Secretary of State's whole obligation to provide is limited by the words "to such extent as he considers necessary to meet all reasonable requirements."

\section{Standard of unreasonableness}

It is well established legal theory that the courts will not interfere with the exercise of a ministerial discretion under such a widely framed power unless the decision was so unreasonable that no reasonable minister could have reached it. This standard of unreasonableness is often illustrated by "the red headed man test." A minister's decision would be upset by the courts if he determined that services would be provided for everyone except red headed men. That leaves wide room for ministerial discretion. In the case in question the Court of Appeal followed that standard legal theory and rejected the patients' claim. One of the judges pointed out that to decide the other way would be to lead the country to the economics of the bottomless pit.

If the patient deprived of treatment by rationing of resources cannot get compensation from the executive with overall responsibility for rationing can he make a successful claim against those responsible at the point of treatment, or non-treatment? A general practitioner has a duty to treat patients on his list. A hospital authority undertakes a duty to treat all patients admitted to the hospital. Do they have any responsibility to anyone else? In other words, could a patient recover damages from a general practitioner who refused to take him on to his list, or from a hospital which refused to admit him. The answer must generally be no, and that patient's remedy must be administrative and political rather than legal.
But once on the general practitioner's list, or once admitted to hospital, what is the level of treatment that the patient is entitled to demand? The doctor must exercise reasonable skill and care, measured by the standard of what is reasonably to be expected from the ordinarily competent practitioner of his class. That standard does not vary, but the treatment required by the standard will vary according to circumstances. A consultant obstetrician cut off by snow in a country hotel on Exmoor would not be expected to deliver a baby in precisely the same manner that he would adopt in a teaching hospital. Similarly, availability of equipment in ordinary circumstances unaffected by emergency may be taken into account by the courts in applying the standard. In a case in 1950 it was held that where it is alleged that a complaint could have been successfully diagnosed by the use of a particular apparatus, regard must be had to the availability of that apparatus in the particular case to decide whether the failure to use it amounts to negligence. ${ }^{3}$

No doctor is under a duty to treat a patient with drugs or equipment which are simply not available. If there is no capacity available at a particular hospital for further patients for haemodialysis no legal liability can arise out of a refusal to accept further patients. But once a patient has been accepted it is strongly arguable that there is a duty to continue treatment for so long as it is doing any good. And so far as the general practitioner is concerned so long as he is allowed by the NHS to prescribe a particular drug or carry out or order a particular screening process, he should base his decision solely on the needs of the individual patient before him, leaving it to others to allocate resources by placing drugs on lists and so forth. The legal test is whether the ordinarily competent practitioner of his class would consider that the treatment, or the investigation, was in the interests of the particular presenting patient regardless of possible interests of others. Of course, that is not to say that the patient should be given whatever he requests.

\section{References}

1 Minerva. Views. BrMed f 1985;290:248.

2 R $v$ Secretary of State for Social Services ex p Hincks. Unreported, Supreme Court Library, (1981) 274.

3 Whitford 0 Hunter (1954) 94 Sol Jo 758.
What precautions should be taken by staff handling hydroftuoric acid and nitric acid? What is the first aid treatment?

The prevention of accidents with inorganic acids is preferable to even the most expert first aid. For adequate prevention safe working practices operated by adequately trained and suitably protected employees are necessary. Training of workers includes instruction in the correct methods of handling acids and the appropriate working practices for their storage and transport. Large quantities of acid should be stored in appropriately marked containers in a designated place and should be transported on trolleys or powered trucks. Hydrofluoric acid must be stored in rubber lined or plastic containers, not in glass, whereas nitric acid should be stored well away from large quantities of metal or organic materials such as wood. Bottles should be carried in baskets that will protect against impact and contain any spillage, and decanting should be carried out with mechanical pouring equipment. Protective clothing consists of an overall or apron, boots, and gloves and cap made from an acid resistant material (PVC or Neoprene). Eye protection (face shields or goggles) must be available. Respiratory protection need not be worn routinely but should be available for emergency use. Premises should have emergency shower facilities and eye wash stations. Staff qualified in first aid should be available.

Rapid first aid is essential. Remove contaminated clothing, under a shower if possible. If the victim is unconscious a clear airway should be provided and maintained. Administer $100 \%$ oxygen if available. If breathing fails mouth to mouth ventilation should not be attempted where the face is contaminated unless a Brook Airway is employed-the Holger Nielsen method may be used. Burns should be washed with copious quantities of tepid water. For hydrofluoric acid burns washing should be followed by the application of magnesium oxide and glycerine paste or calcium gluconate gel (subcutaneous injection of the latter has little advantage over topical application). Some authorities recommend prophylactic calcium in severe hydrofluoric acid burns'; others do not. ${ }^{2}$ - W R LEE, professor of occupational health, Manchester. 1 Browne TD. The treatment of hydrofluoric acid burns. Foumal of the Sociery of Occupational
Medicine 1974;24:80-9.

2 Tepperman PB. Hydrofluoric acid skin burns: addendum. 7 Occup Med 1984:24:79.

What is the reason for painful tender ribs in older women for which no cause can be found?

Tiertz's syndrome is a common explanation for painful tender ribs in older women for which no cause can be found. Obviously other more serious causes must be excluded before this diagnosis is made. The syndrome may present as painful tender enlargement of the sternocostal junction, generally in the area of the fifth, sixth, and seventh ribs. Symptoms are made worse by deep breathing or pressure: In some cases the wearing of a bra may be painful. Examination may show no signs, although painful tender nodules may be palpable. The cause is unknown but the symptoms may follow minor trauma. Some believe that the onset of calcification of costal cartilages may be the aetiological factor. The syndrome is self limiting and the treatment is supportive, with the use of analgesia and heat if necessary. Minor strains of the intercostal muscles occur after coughing or physical effort. These strains are painful and the symptoms long lasting. The treatment again is supportive.-C D R.LIGHTOWLER, consultant orthopaedic surgeon, London. 